\title{
Using Shanghai Municipal Data to Examine the Impact of Education on the Exercise Behavior of Students
}

\author{
Cheah Hon Foong ${ }^{1, *}$ Catur Supriyanto ${ }^{2}$
}

\author{
${ }^{1}$ Shanghai University of Sport, China \\ ${ }^{2}$ Universitas Negeri Surabaya, Indonesia \\ *Corresponding author. Email: cheah@sus.edu.cn
}

\begin{abstract}
The competitive education environment in China encourages students to take additional private tutoring as they advance through their education system. We examine whether their incentive to take extra tutoring classes will undermine their propensity to exercise, potentially affecting their long-term health. Using a survey on sports behavior and consumption for Shanghai residence ages 6 to 17, we found that on average, students that advance through a year in education spend 0.169 fewer days of weekly exercise and are 1.38 percent less likely to spend on training. In other words, when compared to an average sixth-grade student, a twelfth-grade student spends a day less in exercise per week and is 8.3 percent less likely to spend less on sports training. It demonstrated that the additional private lessons reduce leisure time, causing students to cut down on their frequency to exercise. We find that on average, students make up for the lack of exercise and sports training by watching more sports events and spending more on sports expenditure.
\end{abstract}

Keywords: Over-education, Student's exercise behavior, Sports participation.

\section{INTRODUCTION}

There is a consensus that education is fundamental to the well-being of society. Education enhances an individual's standard of living, helping them secure a better career and provide for their family. Education incurs a significant positive externality to society; supplying much-needed high-skilled jobs reduces criminal activities. The Chinese government recognizes the importance of education and offers universal education to students up to 16 [1], [2]. While a student's intellect, motivation, and passion are crucial to learning a particular subject and obtaining a high score in their entrance exam, the education system in China is primarily test-driven. Schools, teachers, and parents want their children to secure the best score possible, frequently at the expense of learning the subject matter. Increase their child's performances in their high school and college entrance examinations (Zhong Kao and gaokao). Parents prepare years in advance, identifying and purchasing real estate in districts with excellent primary and secondary school districts, driving up the prices of good school districts. Parents with fewer means or migrant workers whose child has no access to public schools make up for the lack of good public education resources by loading up with a variety of private tuition and test preparation programs available in the market. The limited access to good public universities and primary and secondary schools has expanded the need for private tutoring and test prep programs (notoriously known as cram schools). Many have opted not to take the college and high school entrance exams for wealthier parents who do not want their children to bear the highly competitive pressure. Instead, they choose to send their child abroad to renowned foreign secondary schools and universities.

The test-driven education system in China, which has led to the rapid growth of private tutoring, has both positives and negatives. First private tutoring supplements the lack of good public education resources. Parents turn to private tutors when they feel that public education cannot meet their education goals. Since education confers an external benefit to society, it indirectly contributes to providing highly skilled jobs and lower criminal activity. However, the growth of private education has raised concerns, especially among families of different wealthy backgrounds. Families with significant means can afford to purchase homes at good school districts, which will drive up housing prices in good education districts across many Chinese metropolitans. Therefore the growth of private tutors has indirectly contributed to creating a gap in 
dividing the education opportunity between the rich and the poor. The rising housing price and the unequal income and education opportunities have raised concerns among government officials. This paper focuses on other unintended consequences from taking too many private lessons, which results in students exercising less because tutoring takes up leisure time that students could spend on sports activities. The literature on sports and exercise behavior has shown that individuals who exercise regularly exercise more than those without a proper routine. Therefore, when students load up on private classes as they advance through the grades, they cut down on sports activities, which reduce their likelihood of resuming a regular exercise schedule once they graduate from high school. Lower exercise and sedentary behavior have long-term consequences on individual health and a country's healthcare infrastructure and public expenditure on healthcare. Realizing the growing sedentary lifestyle of its citizens, the Chinese government elevates the importance of physical education in public schools. It requires students to take fitness tests as part of their education curriculum. In addition, some parents enroll their children in paid sports programs in response to their lack of exercise and the inadequate sports program from school. Therefore, while students exercise less in response to lack of leisure time from private tutoring, some of it is made up of paid sports instructions.

The paper uses data from the Shanghai municipal survey on exercise behavior and sports-related expenditure to examine the effects of education on sports consumption exercise behavior. The data provided by the Shanghai municipal contains questionnaires on a variety of sports behavior of Shanghai residence that enable us to examine the effect of education on students' propensity of exercise (number of practices per week), their tendency to undertake paid sports programs and to watch a sports event. These data allow us to explore the relationship between individual exercise behavior and their propensity to consume sports. For example, we can examine whether students make up for the lack of exercise by increasing sports consumption. The data availability allows us to explore the substitution and complementary effect between sports consumption and sports exercise.

\section{THE PREDICTION ON EDUCATION LEVEL AND THEIR EXERCISE BEHAVIOR}

\subsection{Behavior}

In China, especially in large metropolitan cities of Beijing, Shanghai, Shenzhen, and Guangzhou, having access to a good education provide a better job opportunity, better career trajectory, and an overall better standard of living. This framework has its roots back from the seminal work of Becker (1964), in which an individual accumulates education to increase its earning potential. However, the supply of good schools and universities is minimal, and students must obtain a sufficiently high score in their college entrance examination. Many students and parents feel that relying on public school alone is no guarantee of a good performance in their entrance exam. Many enrolled their children in various test-prep schools or private tutors to supplement their general education. Therefore, as students advance through the grades, they find the subject matters to be more complex and thus rely more on private tutors to supplement public educations. However, the alternative hypothesis is potentially valid given the Chinese government recognizes the importance of having a well-rounded education. Not only does the government incentivize schools to devote more class time to physical education, but many parents also recognize the importance of sports and physical activity by enrolling their children in private extracurricular activities; some of them involve sports training programs. In light of these two possibilities, we propose the following hypothesis and its alternative:

Hypothesis 1: As a student advances through the grades, they devote less time to exercise.

Hypothesis 1A: As a student advances through the grades, they devote more time to exercise

As students advance through the grades, they spend more time on tutor classes and extracurricular activities and less time on leisure activities [4]-[6]. The lower leisure time affects the time spent on exercising and the time spent on sports training and watching a sports event. Conventional economic theory predicts that less leisure time leads to less time devoted to sports training and watching sports events [6], [7]. On the other hand, students could end up substituting the lack of exercise with paid training classes and watching a sports event [8], [9]. Moreover, the alternative hypothesis that fewer exercise leads to a greater propensity to watch sports events is plausible because with advances in computers and wide availability of mobile devices, watching an event via online streaming is far more flexible than paying for a sports program, which is time-intensive and is scheduled at regular intervals. We summarize the two hypothesis and their alternatives below:

Hypothesis 2: As students advance through the grades, they devote less time to a paid sports program. Hypothesis 2A: As students advance through their grades, they devote more time to a paid sports program.

Hypothesis 3: As students advance through the grades, they devote less time watching sports events. 
Hypothesis 3A: As students advance through their grades, they devote more time to watching a sports event.

As students advance through the grades, they may end up spending less time on exercise activities because they take private tutoring and extracurricular activities that consume leisure time [10], [11]. This leads to two possible predictions. First, the lack of exercise and the devotion to sports-related activity increase sportsrelated expenditure because students substitute the lack of sports with more superb purchases of sports-related activities. Another possibility is that the lack of exercise and devotion to sports-related activity reduces sports-related expenditure since sports behavior and the related spending complemented one another. Therefore we propose the following hypothesis and its alternatives:

Hypothesis 4: As student decrease their weekly exercise, they make up for it by increasing sportsrelated expenditure (sports expenditure is a substitute to exercise)

Hypothesis 4A: As student decrease their weekly activity; also reduce their sports-related expenditure (sports expenditure is a complement to exercise)

\section{METHODS}

To understand its residents' expenditure and sporting habits, in 2015, the Shanghai municipal began to collect data from private residences by distributing questionnaires at the township level. The questionnaires collected basic information such as the location of the home, gender, level of education, sports habits, and sports-related expenditures such as the amount of daily exercise performed in a week, the type of sports followed regularly, and spending on sports attire, sports equipment, subscriptions and tickets to sports events. The dataset contains two forms of survey data. First, the offline survey is administered top-down at a township level, instructing surveyors to select participants within their jurisdiction randomly. Second, the online survey, introduced in 2016, publicly displays questionnaires online to users visiting the site. Since participants from the online surveys may not be randomly assigned similarly to their offline counterparts, caution should be taken when analyzing the data set, with the possibility of selection bias in which online participants have a greater interest in sports than the general public. Nevertheless, online surveys provided much information since more than half $(57 \%)$ of the participants were collected from the Internet.

\section{FINDINGS AND DISCUSSION}

After the data collection process, the descriptive statistics was done, and the result can be seen in the following table:

Table 1. Popular choices of exercise from 2015, 2016 questionnaires

\begin{tabular}{|l|c|c|}
\multicolumn{1}{|c|}{ Mode of exercise } & Primary $(2015,2016)$ & Secondary $(2015,2016)$ \\
\hline Running & $11.62 \%$ & $8.71 \%$ \\
\hline Walking & $10.56 \%$ & $7.28 \%$ \\
\hline Recreational games & $9.70 \%$ & $3.06 \%$ \\
\hline Basketball & $8.05 \%$ & $9.06 \%$ \\
\hline Badminton & $7.92 \%$ & $11.93 \%$ \\
\hline Swimming & $7.16 \%$ & $9.39 \%$ \\
\hline Soccer & $6.28 \%$ & $5.79 \%$ \\
\hline Rope skipping & $4.44 \%$ & $5.31 \%$ \\
\hline Table tennis & $3.55 \%$ & $4.73 \%$ \\
\hline
\end{tabular}

Table 2. Sports expenditure at different regions in Shanghai [12]

\begin{tabular}{|l|c|c|c|c|}
\multicolumn{1}{r|}{ Region } & Mean & $25^{\text {th }}$ percentile & $50^{\text {th }}$ percentile & $75^{\text {th }}$ percentile \\
\hline Central & 9520 & 800 & 2100 & 6000 \\
\hline Pudong New Area & 5689 & 780 & 1700 & 4868 \\
\hline Suburban & 5805 & 800 & 1920 & 4338 \\
\hline Remote- suburban & 6224 & 730 & 1845 & 4456 \\
\hline
\end{tabular}

We should be cautious with the average figures reported in table 2 ; there is a significant variation within the consumption behavior of Shanghai residence. Moreover, $13 \%$ of the respondents say no sports-related 
expenditure. Even when we focus only on favorable prices, most respondents spend well below the average amount, while a small minority was spending a significant amount, skewing the average well above its median.

We did four regression analyses to confirm the issue. The first regression used the following framework:

$$
\text { exercise }=\beta_{10}+\beta_{11} \text { education }+\Gamma X_{1}+\varepsilon_{1}
$$

Exercise: number of practices per week

Education: years of education

$\mathrm{X}_{1}$ : other factors that determine movement (gender, preference for sports location, expenditure)

Prediction: variable $\beta_{11}$ to be negative

The first regression shows that the effect of education on sports is weaker (-0.121 days of exercise per week), meaning that a grade 12 student on average exercises 0.7 days fewer per week than a grade 6 student. However, the effect is statistically significant at a $1 \%$ percent level. Even with the Tobit specification, allowing individuals to choose zero exercises as their optimal choice Tobin, (1958) and Wooldridge (2010), the result remains significant to a 1 percent level [15][18]. Our regression result also fits the consensus that males participate in sport more than females [19], [20].

The second regression framework used the following framework below:

training $=\beta_{20}+\beta_{21}$ education $+\Gamma X_{2}+\varepsilon_{2}$

Training: dummy variable on whether students pay for training

Education: years of education

$\mathrm{X}_{2}$ : other factors that determine exercise (gender, preference for sports location, expenditure)

Prediction: variable $\beta_{21}$ to be negative
The result indicates that being a sports spectator increases the chance of spending on sports training by about 43.8 percent. Those who exercise an additional day in their weekly routine are 2.2 percent more likely to engage in sports.

The third regression framework used the following framework below:

spectator $=\beta_{30}+\beta_{31}$ education $+\Gamma X_{3}+\varepsilon_{3}$

Spectator: dummy variable on watching sports event Education: years of education

$\mathrm{X}_{3}$ : other factors that determine exercise (gender, preference for sports, location, expenditure)

Prediction: Variable $\beta_{31}$ can be both positive or negative

The results indicate that, on average, those who spend an additional 1000 yuan on ticket sales and have a 0.5 percent higher chance of watching sports events. The fourth regression used the following framework:

exp enditure $=\beta_{40}+\beta_{41}$ education $+\Gamma X_{4}+\varepsilon_{4}$

Expenditure: sports expenditure in (thousands of yuan) Education: years of education

$\mathrm{X}_{2}$ : other factors that determine exercise (gender, preference for sports, location, fee)

Prediction: Variable $\beta_{41}$ can be both positive or negative

The result indicates that, on average, students who advanced in their grades purchase more sports equipment and spend more money on subscriptions and sports events, showing that students that spend less time on sport tend to buy more equipment, subscription, and tickets to a sports event. The summary of the full result can be seen below:

Table 3. The effect of education on various sports expenditure

\begin{tabular}{|c|c|c|c|c|c|c|}
\hline Dependent variable & Attire & Equipment & Subscription & Training & Spectator & $\begin{array}{c}\text { Travel and } \\
\text { others }\end{array}$ \\
\hline Schooling age & $\begin{array}{l}0.0046 \\
(0.00367)\end{array}$ & $\begin{array}{l}0.0229 * \star \\
(0.0037)\end{array}$ & $\begin{array}{l}0.0501^{* *} \\
(0.00428)\end{array}$ & $\begin{array}{l}-0.0086^{*} \\
(0.0043)\end{array}$ & $\begin{array}{l}0.0237^{\star \star} \\
(0.0044)\end{array}$ & $\begin{array}{l}0.00119 \\
(0.0049)\end{array}$ \\
\hline Sport training & $\begin{array}{l}0.2919 * \star \\
(0.0262)\end{array}$ & $\begin{array}{l}0.4583^{* *} \\
(0.0272)\end{array}$ & $\begin{array}{l}0.4818^{\star \star} \\
(0.0331)\end{array}$ & $\begin{array}{l}0.8826^{\star *} \\
(0.03317)\end{array}$ & $\begin{array}{l}0.5050 * * \\
(129.90)\end{array}$ & $\begin{array}{l}0.5768^{\star *} \\
(0.0385)\end{array}$ \\
\hline Sport spectator & $\begin{array}{l}-0.1028^{* *} \\
(0.0278)\end{array}$ & $\begin{array}{l}0.1866^{\star *} \\
(0.0283)\end{array}$ & $\begin{array}{l}0.3335^{\star *} \\
(0.0336)\end{array}$ & $\begin{array}{l}-0.0455 \\
(0.0332) \\
\end{array}$ & $\begin{array}{l}0.34773^{* *} \\
(0.03467)\end{array}$ & $\begin{array}{l}0.2072^{* *} \\
(0.0391)\end{array}$ \\
\hline Daily exercise & $\begin{array}{l}0.0318^{\star *} \\
(0.0081)\end{array}$ & $\begin{array}{l}0.0533^{* *} \\
(0.0090)\end{array}$ & $\begin{array}{l}0.03805^{\star \star} \\
(0.0109)\end{array}$ & $\begin{array}{l}0.0596^{\star \star} \\
(0.0112)\end{array}$ & $\begin{array}{l}0.0688^{* \star} \\
(0.0117)\end{array}$ & $\begin{array}{l}0.0900^{\star *} \\
(0.0130)\end{array}$ \\
\hline Male & $\begin{array}{l}0.0918^{* *} \\
(0.0239)\end{array}$ & $\begin{array}{l}0.1435^{\star *} \\
(0.0248)\end{array}$ & $\begin{array}{l}0.0869 * * \\
(0.0294)\end{array}$ & $\begin{array}{l}0.0946^{\star \star} \\
(0.03024)\end{array}$ & $\begin{array}{l}0.1199 * \star \\
(0.0311)\end{array}$ & $\begin{array}{l}0.1249 * \star \\
(0.0342)\end{array}$ \\
\hline
\end{tabular}

Based on our regression analysis, we fail to reject the following hypothesis:
Hypothesis 1: As a student advances through the grades they devote less time to exercise. 
Hypothesis 2: As students advance through the grades, they devote less time to a paid sports program.

Our data has shown that students advance through their grades; they exercise less and participate less in the paid sports program. This finding is consistent with the narrative of less leisure time as students load up on private lessons to increase their chances to pass the high school and college entrance exams. Since exercise activity and sports programs are time-intensive, losing leisure time naturally leads to lower time spent on exercising and sports activities.

Our regression analysis has rejected the following hypothesis in favor of the alternative idea:

\section{Hypothesis 3A: As a student advances through the grades they devote more time on watching sports events}

While watching sports events is time-intensive, recent technological advances allow many students to watch from their devices. Therefore, students can be more flexible with their leisure time when watching a particular sports event from their mobile devices. Moreover, the data also suggests that participating in sports and watching sports events are substitutes. Students who advanced in their grades cut down on sports participation but make up for the loss by watching more sports events.

Our regression result is inconclusive regarding exercise behavior and total sports expenditure. While the reduction in exercise does not lead to greater overall sports consumption, the reduction in movement leads to an increase in specific categories of sports expenditure: sports equipment, subscription to sports magazines, and tickets to sports events. This finding reinforces the substitution nature between exercise and sports consumption. As students advance through the grades, they exercise less. However, they make up for the lack of exercise by purchasing sports equipment, tickets to sports events, and subscriptions to sports magazines. Therefore, for particular sports expenditure, we fail to reject the following hypothesis:

Hypothesis 4: As student decrease their weekly exercise, they make up for it by increasing sportsrelated expenditure (sports expenditure is a substitute to exercise)

At the time of writing, the Chinese government has imposed several measures to reduce the overall cost of education and the overemphasis on education through after-school lessons. The reaction so far has been mixed. On the one hand, many parents applaud the government measure because it reduces their peer pressure to send their child to after-school lessons, reducing the excessive monetary burden and allowing their kid more incredible time to devote to exercise and sports-related activities. On the other hand, many companies in the education sector experience an abrupt adjustment to become non-profit entities (a requirement by the government) and to reorient their lesson towards more extracurricular activities. Moreover, some parents may have to provide their after-school classes to their children, especially when their child fails to learn a specific subject in school adequately. Regardless, most agree that the latest measure taken is a conscious effort to reorient the education industry from "cram schools" to one that prioritizes sports-related activities.

Given the importance of exercise and sports on long-term health, students' choice to cut back on activity may lead to a greater likelihood of a sedentary lifestyle soon. The Chinese government recognizes this trend and has elevated the importance of physical education in public schools to incentivize students to invest more into exercise and physical education. The government has taken various measures to limit the market of private tutoring and cram schools [21]. While we agree with the government's outlook of elevating the importance of sports and exercise in public school, we also recommend that public schools should focus on raising health awareness and the importance of exercise because it provides additional incentive for parents to invest in their child's physical education [16]. On the other hand, we cannot comment on the government's role in limiting private tutoring since the outcome from such measures remains to be seen.

To some extent, we believe that the rise of private tutoring is the consumer's response to the lack of good public education resources. Therefore, placing restrictions on private tutoring not only reduces the external benefit from education but may further the divide between those with ample opportunities (wellto-do) for good education and those without (lowincome families). Therefore, the government should take an active approach to promote greater awareness of the importance of sports, exercise, and leisure time to provide parents with the necessary information to make an informed choice.

\section{CONCLUSION}

This study investigates the impact of Education on the exercise behavior of students by using Shanghai Municipal Data. The result showed that as students advance in their grades, they exercise less. Moreover, as students move in their rates, they spend less on sports training. The result indicates that students advance in their grades; they substitute fewer sports with watching sports. As students move in their rates, it has an insignificant effect on total sports expenditure but a 
negligible impact on spending on sports equipment, sports subscriptions, and watching sports events.

\section{ACKNOWLEDGMENTS}

The author acknowledges the Shanghai Municipal data provider to provide the data.

\section{REFERENCES}

[1] Q. Kan, "A Brief Introduction to The Chinese Education System," OpenLearn, 2019. https://www.open.edu/openlearn/education/briefintroduction-the-chinese-education-system.

[2] Z. Xinying, "China Has The World's Largest Education System," China Daily, 2017. https://www.chinadaily.com.cn/china/201709/28/content_32606890.htm.

[3] G. S. Becker, Human Capital: A Theoretical and Empirical Analysis, with Special Reference to Education, 3rd ed. New York: Columbia University Press, 1964.

[4] J. Ruseski and K. Maresova, "Economic Freedom, Sports Policy, and Individual Participation in Physical Activity: An International Comparison," Contemp. Econ. Policy, vol. 32, no. 1, pp. 42-55, 2014, [Online]. Available: http://hdl.handle.net/10.1111/coep.12027.

[5] F. B. Adrian Bauman 1 Tien Chey, Cora L Craig, Barbara E Ainsworth, James F Sallis, Heather R Bowles, Maria Hagstromer, Michael Sjostrom, Michael Pratt, IPS Group, "The International Prevalence Study on Physical Activity: Results from 20 Countries," Int. J. Behav. Nutr. Phys. Act., vol. 6, no. 21, pp. 1-11, 2009, DOI: 10.1186/1479-5868-6-21.

[6] T. Kokolakakis Castellanos-García, P., \& LeraLópez, F., "Differences in Formal and Informal Sports Participation at Regional Level in England," Int. J. Sport Policy Polit., vol. 9, no. 3, pp. 491-504, 2017, DOI: 10.1080/19406940.2017.1287757.

[7] P. Downward and S. Rasciute, "No Man is an Island Entire of Itself': The Hidden Effect of Peers on Physical Activity: John Donne, Meditation XVII," Soc. Sci. Med., vol. 169, pp. 149-156, 2016, DOI: 10.1016/j.socscimed.2016.09.038.

[8] M. A. Petilli, L. Rinaldi, D. C. Trisolini, L. Girelli, L. P. Vecchio, and R. Daini, "How Difficult is it for Adolescents to Maintain Attention? The Differential Effects of Video Games and Sports," Q. J. Exp. Psychol., vol. 73, no. 6, pp. 968-982, 2020, DOI: $10.1177 / 1747021820908499$.

[9] P. J. C. Adachi and T. Willoughby, "Does Playing Sports Video Games Predict Increased Involvement in Real-life Sports Over Several
Years Among Older Adolescents and Emerging Adults?" J. Youth Adolesc., vol. 45, no. 2, pp. 391-401, 2016, DOI: 10.1007/s10964-015-03122.

[10] P. Downward and S. Rasciute, "The Relative Demands for Sports and Leisure in England," Eur. Sport Manag. Q., vol. 10., no. 2, pp. 189-214, 2010, DOI: 10.1080/16184740903552037.

[11] B. Humphreys and J. Ruseski, "An Economic Analysis of Participation and Time Spent in Physical Activity," BE J. Econ. Anal. Policy, vol. 11, no. 1, pp. 1-47, 2011, DOI: 10.2202/19351682.2522 .

[12] P. R. of China, "Government of the People's Republic of China," www.gov.cn., 2016..

[13] J. Tobin, "Estimation of Relationships for Limited Dependent Variables," Econom. J. Econom. Soc., vol. 26, no. 1, pp. 24-36, 1958, [Online]. Available:

https://cowles.yale.edu/sites/default/files/files/pu b/d00/d0003-r.pdf.

[14] J. M. Wooldridge, Econometric Analysis of Cross Section and Panel Data, 2nd ed. United Kingdom: MIT Press, 2010.

[15] J. E. Ruseski, B. Humphreys, K. Hallmann, and C. Breuer, "Family Structure, Time Constraints, and Sport Participation," Eur. Rev. Phys. Act., vol. 8, no. 2, pp. 57-66, 2011, DOI: $10.1007 / \mathrm{s} 11556-$ 011-0084-y.

[16] P. Downward, K. Hallmann, and T. Pawlowski, "Assessing Parental Impact on The Sports Participation of Children: a Socio-economic Analysis of The UK," Eur. J. Sports Sci., vol. 14 , no. $1, \quad$ pp. $84-90, \quad 2014$, DOI: 10.1080/17461391.2013.805250.

[17] F. Liu, E. Black, J. Algina, C. Cavanaugh, and K. Dawson, "The Validation of One Parental Involvement Measurement in Virtual Schooling," J. Interact. Online Learn., vol. 9, no. 2, pp. 105$132,2010$.

[18] E. \& E. Thibaut John \& Vos, Steven \& Scheerder, Jeroen, "Time and Money Expenditure in Sports Participation: The Role of Income in Consuming The Most Practiced Sports Activities in Flanders," Sport Manag. Rev. Elsevier, vol. 20, no. 5, pp. 455-467, 2017, DOI: 10.1016/j.smr.2016.12.002.

[19] P. Downward and S. Rasciute, "Exploring The Covariates of Sports Participation for Health: An Analysis of Males and Females in England," $J$. Sports Sci., vol. 33, no. 1, pp. 67-76, 2015, DOI: 10.1080/02640414.2014.924056.

[20] B. Eberth and M. D.Smith, "Modelling The Participation Decision and Duration of Sporting Activity in Scotland," Econ. Model., vol. 27, no. 4, pp. 822-834, 2010, DOI: https://doi.org/10.1016/j.econmod.2009.10.003. 
[21] C. Feng and J. Zhang, “'What's The End Game for China's Crackdown on Private Tutoring? Beijing Wants a Fair and Sustainable Society,"” South China Morning Post, 2021. https://www.scmp.com/business/chinabusiness/article/3146644/whats-end-gamechinas-crackdown-private-tutoring-beijing. 